\title{
Toll-like receptor signaling adapter proteins govern spread of neuropathic pain and recovery following nerve injury in male mice
}

\author{
Jennifer A Stokes ${ }^{1,2}$, Jonathan Cheung ${ }^{1,2}$, Kelly Eddinger ${ }^{1,2}$, Maripat Corr ${ }^{3}$ and Tony $L$ Yaksh ${ }^{1,2^{*}}$
}

\begin{abstract}
Background: Spinal Toll-like receptors (TLRs) and signaling intermediaries have been implicated in persistent pain states. We examined the roles of two major TLR signaling pathways and selected TLRs in a mononeuropathic allodynia.

Methods: L5 spinal nerve ligation (SNL) was performed in wild type (WT, C57BL/6) male and female mice and in

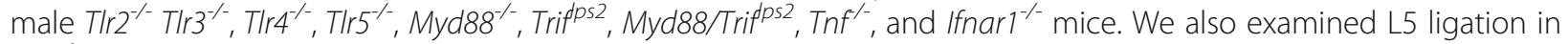
$T / r 4^{-1}$ female mice. We examined tactile allodynia using von Frey hairs. Iba-1 (microglia) and GFAP (astrocytes) were assessed in spinal cords by immunostaining. Tactile thresholds were analyzed by 1- and 2-way ANOVA and the Bonferroni post hoc test was used.

Results: In WT male and female mice, SNL lesions resulted in a persistent and robust ipsilateral, tactile allodynia. In males with TLR2, 3, 4, or 5 deficiencies, tactile allodynia was significantly, but incompletely, reversed (approximately 50\%) as compared to WT. This effect was not seen in female T/r $4^{-\%}$ mice. Increases in ipsilateral lumbar Iba-1 and GFAP were seen in mutant and WT mice. Mice deficient in MyD88, or MyD88 and TRIF, showed an approximately $50 \%$ reduction in withdrawal thresholds and reduced ipsilateral Iba- 1 . In contrast, TRIF and interferon receptor null mice developed a profound ipsilateral and contralateral tactile allodynia. In lumbar sections of the spinal cords, we observed a greater increase in Iba-1 immunoreactivity in the TRIF-signaling deficient mice as compared to WT, but no significant increase in GFAP. Removing MyD88 abrogated the contralateral allodynia in the TRIF signaling-deficient mice. Conversely, IFN $\beta$, released downstream to TRIF signaling, administered intrathecally, temporarily reversed the tactile allodynia.
\end{abstract}

Conclusions: These observations suggest a critical role for the MyD88 pathway in initiating neuropathic pain, but a distinct role for the TRIF pathway and interferon in regulating neuropathic pain phenotypes in male mice.

Keywords: Allodynia, Hyperalgesia, Interferon-beta, MyD88, Spinal nerve ligation, Toll-like receptors, TRIF

\section{Background}

Clinical symptoms arising from physical injury to the peripheral nerve include initiation of a pain behavior phenotype by otherwise innocuous stimuli (allodynia) [1]. Though complex, a number of components have been identified as associated with this pain phenotype. Such a behavioral phenotype has been identified in

\footnotetext{
* Correspondence: TYAKSH@UCSD.EDU

'Department of Pharmacology, University of California, 9500 Gilman Dr. MC 0636, La Jolla, San Diego, CA 92093-0636, USA

${ }^{2}$ Department of Anesthesiology, University of California, 9500 Gilman Dr. MC 0818, La Jolla, San Diego, CA 92093-0818, USA

Full list of author information is available at the end of the article
}

preclinical mononeuropathy models (e.g., spinal nerve ligation (SNL)), where a robust tactile allodynia [2-4] and evidence of an aversive state [5] have been noted. Based on these preclinical behavioral models, many contributors to the post-nerve injury pain state have been implicated, including changes in dorsal root ganglion (DRG), transcription factor expression, and activation of spinal glia [6-9], along with the appearance of inflammatory mediators such as tumor necrosis factor (TNF) [6,10-13]. Thus, after ligation of the L5 nerve, expression of activation transcription factor 3 (ATF3) in the DRG is increased $[14,15]$. In the spinal cord, microglia and astrocytes display 
morphological signs of activation in the ipsilateral lumbar enlargement of the spinal cord $[16,17]$. The reduction of injury-evoked hyperalgesia, with intrathecal (IT) inhibitors of glial activation, supports the contribution of glia as a possible target [18-22].

Toll-like receptors (TLRs) are a family of 14 identified receptors that play a key recognition role in the innate immune response. Several TLRs activate multiple downstream cascades that variously activate NF- $\mathrm{kB}$ dependent cytokine production and NF- $\mathrm{kB}$ independent interferon (IFN) induction [23,24]. These receptors are expressed on cells active in innate immunity, but are also found on glial (microglia and astrocytes) and non-glial (spinal and DRG neurons) CNS cells [25-27]. The role of peripheral and central glial activation in the neuropathic pain state raises the likelihood that TLRs may play a role in mediating spinal sensitization, initiated by peripheral nerve injury [28-30]. Current research indeed supports the importance of TLR signaling in neuropathic pain [31-36] and in persistent arthritic models where a neuropathic transition has been hypothesized [37-39]. In particular, TLR4 has been implicated as playing a critical role in the development of neuropathic pain in male rodents, but this may not be universally true in females [34,40-42]. While these studies indicate that TLRs play a role in these models, the cascades through which they mediate behaviorally defined pain states remain unclear.

As indicated schematically in Figure 1A, TLRs signal through a limited number of adaptor proteins that converge in signaling through myeloid differentiation primary response gene 88 (MyD88) or TIR-domain-containing adapter-inducing IFN $\beta$ (TRIF). The MyD88 activation pathway, common to all TLRs except TLR3, leads to activation of NF- $\mathrm{KB}$, producing pro-inflammatory cytokines such as TNF and IL-1 $\beta$ [43]. In contrast, the TRIF pathway is shared only by TLR3 and TLR4 signaling, and can result, by activation of IFN regulatory factors (IRF), in IFN $\beta$ secretion [44-46].

In a recent publication, we showed that a prominent tactile allodynia was produced by IT TLR agonists in

A

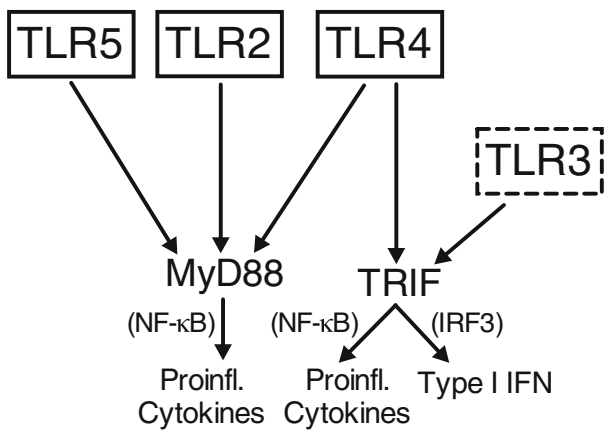

B

\begin{tabular}{|c|c|c|}
\hline $\begin{array}{l}\text { Target } \\
\text { Protein }\end{array}$ & $\begin{array}{c}\text { Genotype } \\
\text { Nomenclature }\end{array}$ & Type of Protein Deficiency \\
\hline TLR2 & $T / r 2^{\%}$ & TLR2 whole-body knock-out \\
\hline TLR3 & $T / r 3^{\%}$ & TLR3 whole-body knock-out \\
\hline TLR4 & $T / r 4^{\prime-~}$ & TLR4 whole-body knock-out \\
\hline TLR5 & $T / r 5^{\prime-}$ & TLR5 whole-body knock-out \\
\hline TNF & $\operatorname{Tnf}^{\prime-}$ & TNF whole-body knock-out \\
\hline TRIF & Trif $^{\text {ps2 }}$ & $\begin{array}{l}\text { TRIF adaptor protein point-mutation on the } \\
\text { ticam1 gene }\end{array}$ \\
\hline MyD88 & Myd88 & MyD88 whole-body knock-out \\
\hline $\begin{array}{l}\text { MyD88 } \\
\text { and } \\
\text { TRIF }\end{array}$ & Myd88 $\%$ Trif ${ }^{\rho s 2}$ & $\begin{array}{l}\text { MyD } 88 \text { whole-body knock-out and TRIF } \\
\text { adaptor protein point-mutation on the ticam } 1 \\
\text { gene }\end{array}$ \\
\hline IFNAR & Ifnar & $\begin{array}{l}\text { Alpha chain of the IFN receptor whole body } \\
\text { knock-out, which binds both IFNa and IFN } \beta\end{array}$ \\
\hline
\end{tabular}

Figure 1 Schematic of the TLR pathways. (A) This figure highlights the key TLRs and their relevant pathways in this paper. TLR2, TLR4, and TLR5 are found on the cell surface, while TLR3 is in the cell endosomes. MyD88 is a key adaptor protein for all TLRs except TLR3. TLR3 and TLR4 signal through TRIF, resulting predominantly in type I interferon production. (B) This table summarizes the strains of mice used in the presented studies and the nomenclature used throughout the paper. 
male mice. These actions had several defining characteristics, namely i) spinal TLR2, 3, and 4 ligands initiate activation, though their respective receptors, and produce allodynia through TIRAP and TRIF signaling; ii) spinal TLR4 allodynia-inducing signaling is TNF dependent and TLR3 is TNF independent; and iii) unexpectedly, TRIF pathway activation repressed TLR4-induced allodynia, likely by an effect evoked by IFN $\beta$ production and signaling [47]. In the following study, we have extended this systematic assessment of the roles of individual spinal TLRs and the MyD88 and TRIF adaptor proteins in tactile allodynia and surrogate marker activation associated with the L5 SNL mononeuropathy model in male mice. The results herein, regarding the respective TLR-null male mice, show a strong correlation with the hypothesized role of spinal TLRs in initiating and regulating a persistent hyperalgesic state. Over the course of this work, it was observed that the nerve injury-induced tactile allodynia was comparable in male and female mice; however, given the recent report of a difference in TLR4 mediated spinal pain state [41], we also examined L5 SNL in $T l r 4^{-/}$females.

\section{Methods}

Animals

All animal experiments were carried out according to protocols approved by the Institutional Animal Care and Use Committee of the University of California, San Diego (under the Guide for Care and Use of Laboratory Animals, National Institutes of Health publication 85-23, Bethesda, MD, USA). Mice were housed up to four per standard cage at room temperature and maintained on a 12-hour light/ dark cycle (lights on at 07:00 AM). Testing was performed during the light cycle; food and water were available ad libitum. C57BL/6 mice (male, 25-30 g; female 20-25 g) were purchased from Harlan (Indianapolis, IN, USA). Tlr $2^{-/}$, $\mathrm{Tlr}^{-/}$, $\mathrm{Tlr} 4^{--}$, and $\mathrm{Myd} 88^{-/-}$mice were a gift from Dr. S. Akira (Osaka University, Japan) [48-50] and were bred for 10 generations onto the C57BL/6 background. Trif ${ }^{p s 2}$ mice were a gift from Dr. B. Beutler (UT Southwestern, TX, USA) and were directly generated on the C57BL/6 background [51]. The appropriate strains were intercrossed to generate $M y d 88 / \operatorname{Trif} f^{f p s 2}$ mice. Tlr $5^{-1}$ and $\operatorname{Tnf}^{/-}$mice were purchased from The Jackson Laboratory. Ifnar $1^{-/}$mice were originally obtained from B\&K Universal Limited (Hull, UK) and backcrossed over 10 generations onto the C57BL/6 background. $\operatorname{Irf} 3^{-/}$and $\operatorname{Irf} 7^{/-}$were a gift from T. Taniguchi (University of Tokyo, Japan) $[52,53]$. Figure $1 \mathrm{~B}$ lists the mouse genotypes and nomenclature used throughout the paper. Additional studies were performed with female C57BL/6 female Tlr4 ${ }^{-/}$mice.

\section{L5 spinal nerve ligation model for neuropathic pain}

Ligation of the L5 spinal nerve was performed as previously described [3]. Briefly, mice were anesthetized in a box of $2.5 \%$ vaporized isoflurane, with $2 \%$ oxygen and $2 \%$ room air, then placed in a nose cone for breathable anesthetic (2\% isoflurane). The L5 spinal nerve root was surgically located, exposed and permanently ligated. The surgical opening was sutured and the mouse was closely monitored and allowed to recover in a heated cage until all reflexes were normal. Each mouse was assessed for any mobility impairments, and if none were present, then cleared for study. For the sham operation, the L5 spinal nerve is surgically exposed, but not ligated. Tactile threshold testing is carried out on days $7,9,12$, and 14 post-surgery.

\section{Behavioral tests}

Mechanical sensitivity was assessed using the von Frey up-down method. Filaments with values ranging from $2.44 \mathrm{~g}$ to $4.31 \mathrm{~g}(0.03 \mathrm{~g}$ to $2.00 \mathrm{~g})$ were applied to the paw as previously described [54]. The 50\% probability withdrawal threshold (in principal, the calculated force to which an animal reacts to $50 \%$ of the presentations) was recorded. The results from the ipsilateral (left) and contralateral (right) paws are graphed separately to show the unilateral tactile allodynia that results from the L5 SNL. Baseline tactile thresholds for all mouse strains used were compared via 1-way ANOVA and no significant differences were found in baseline thresholds.

\section{Intrathecal (IT) injection and drug delivery}

The intrathecal needle placement procedure for the IT IFN $\beta(100 \mathrm{ng} / 5 \mu \mathrm{L})$ and IT vehicle $(0.1 \% \mathrm{BSA})$ treatment was performed as previously described $[36,55]$. Briefly, mice were induced with $3 \%$ isoflurane (with $2 \%$ oxygen and $2 \%$ room air) in a chamber until a loss of the righting reflex was observed. A 1" 30-gauge needle attached to a $50 \mu \mathrm{L}$ Hamilton syringe was inserted between the L5 and L6 vertebrae, evoking a tail flick reflex. Following recovery from anesthesia, as evidenced by a vigorous righting reflex and spontaneous ambulation, typically around 1-2 minutes, mice were evaluated for motor coordination and muscle tone. Tactile thresholds were measured using the up-down application of von Frey hairs along the following time course: 0 (baseline), 120-, and 240-minutes, and 24-h after IT treatment. IFN $\beta$ (Chemicon, $100 \mathrm{ng} / 5 \mu \mathrm{L}$ in $0.1 \% \mathrm{BSA}$ ) was administered intrathecally as a post-treatment, 12 days after L5 SNL. In a separate group of mice, IFN $\beta(7,500 \mathrm{U} / 100 \mu \mathrm{L})$ or vehicle was administered i.p. on day 12 . Tactile thresholds were measured using the up-down application of von Frey hairs along the following time course: 0 (baseline), 120-, and 240-minutes, and 24-h after i.p. treatment. In a third cohort of mice, IFN $\beta(7,500 \mathrm{U} / 100 \mu \mathrm{L})$ or vehicle was administered i.p. as a pre-treatment on day 0 (before L5 SNL), and days 2, 3, 4, 5, 6, and 7 after L5 SNL. 


\section{Immunohistochemistry}

Mice were deeply anesthetized with euthasol and perfused intracardially with $0.9 \%$ saline followed by $4 \%$ paraformaldehyde. The lumbar spinal cord and L4-L6 DRGs were removed, post-fixed in $4 \%$ paraformaldehyde over-night, and cryoprotected in 30\% sucrose. Spinal cord sections (L4-L6) of the spinal cord were cut as free-floating sections $(30 \mu \mathrm{m})$. Tissue sections were incubated with anti-GFAP antibody (1:20,000, Chemicon), and anti-Iba1 antibody (1:1,000, Wako). Binding sites were visualized with secondary antibodies conjugated with fluoro-Alexa-488 and Alexa-594 (1:500, Molecular Probes). Images were captured by Leica TCS SP5 confocal imaging system and quantified using ImageJ64 v.1.47 software. Glia reactivity is characterized by an increase in the number of cells and in the cell morphology (rounding of the cell bodies and thickening of processes) leading to an increase in labeling with increasing glia reactivity. Staining for microglia (Iba1) and astrocyte (GFAP) were each quantified by measuring the total integrated intensity area of pixels divided by the total number of pixels in a standardized area of the dorsal horn (background). The investigator was blinded to experimental conditions during the quantification. Staining intensity was examined in laminae I-III of the superficial dorsal horn with four to five sections (separated by at least $180 \mu \mathrm{m}$ ) examined per animal and three to four animals per experimental condition. Only the areas above a background pixel intensity threshold were included. An increase in the integrated intensity/pixel area for Iba1 and GFAP staining was interpreted to signify microglia and astrocyte reactivity, respectively. All data are presented as fold change from the background sample. Each mouse had its own background sample taken per tissue section from the deeper lamina to control for staining variation. Background values were initially divided into ipsilateral and contralateral halves and assessed for staining intensity as described above. The ipsilateral value was divided by the contralateral value to ensure that the background sample was consistent with an ipsi/contra value of 1 . Iba-1 background values were $1.04 \pm 0.04$ and GFAP values $0.98 \pm 0.08$, confirming an even background staining. Statistics were performed on raw data values.

ATF3 staining was assessed by counting the number of cells with ATF3 positive nuclei. The L5 ipsilateral and contralateral DRGs were cut in transverse sections $(10 \mu \mathrm{m})$ and mounted on glass slides. DRGs were incubated with anti-ATF3 (1:1,000, Santa Cruz) and DAPI. Binding sites were visualized with secondary antibodies conjugated with fluoro-Alexa-488. All quantified sections were separated by at least $60 \mu \mathrm{m}$. ATF3 positive nuclei were counted (one section per animal) and three to four animals are included for each group.

\section{Statistics}

Data are presented as group mean \pm SEM. Tactile threshold time course curves (plotted as the mean \pm SEM vs. time after treatment) were analyzed with a one-way analysis of variance (ANOVA) with repeated measures over time, followed by Dunnett's post hoc test to compare each time point to the same group's baseline. Second, to compare behavior between the two mouse strains, a 2-way ANOVA and Bonferroni post hoc test was used comparing mouse group and treatment. For staining intensity data was compared across mouse strains and ipsilateral vs. contralateral with a 2-way ANOVA followed by Bonferroni post hoc test. All analyses employed Prism statistical software, CA, USA.

\section{Results}

\section{Contributions of TLR signaling to allodynia in spinal nerve ligation}

Unilateral L5 SNL model produces a robust ipsilateral reduction (i.e., from $1.7 \mathrm{~g}$ to $<0.2 \mathrm{~g}$ in the ipsilateral paw (Figure $2 \mathrm{~A}$ ), versus $1.7 \mathrm{~g}$ to $1-1.5 \mathrm{~g}$ in the contralateral paw). Similar results were observed in the wild type (WT) female mice in the tactile stimulus required to initiate a withdrawal of the stimulated paw (Additional file 1: Figure S1). In $\mathrm{Tl} r 2^{-/}, \mathrm{Tlr} 3^{-/}$, and $\mathrm{Tl} r 5^{-/}$mice, there was no change in pre-surgery tactile baselines as compared to WT mice (Figure 2); however, in such mice, there was a persistent and significant reduction in tactile allodynia (Figure 2B-E). Tlr $4^{-/-}$mice had more severe allodynia on days 7 and 9 and then recovered to the $50 \%$ level on days 12 and 14 (Figure 2E). In contrast to the male $\mathrm{Tlr}_{4} 4^{--}$mice, the female $\mathrm{Tlr} 4^{-/-}$mice did not show a reduction in the observed tactile allodynia (Additional file 1: Figure S1).

TLR2 and TLR5 signal through MyD88, and TLR3 signals through TRIF. TLR4 utilizes both the MyD88 and TRIF pathways (Figure 1A). Both $M y d 88^{-/} /$Trif $^{\text {pps } 2}$ and $M y d 88^{-/}$mice after SNL had an ipsilateral paw threshold that was significantly higher than C57BL/6 mice (Figure 3A,C). Surprisingly, mice deficient in TRIF signaling produced a robust tactile allodynia in both the ipsilateral and contralateral paws following SNL (Figure 3B). This suggests that the TRIF pathway is involved in the absence of bilateral effects produced by an otherwise unilateral mononeuropathy. Since the $M y d 88^{-/} / T_{r i f} f^{p s 2}$ mice only developed ipsilateral pain-like behavior, MyD88 is required for contralateral allodynia to develop (Figure 3C).

Since these mice are deficient in immune response signaling, we wanted to ascertain that surgery itself was not initiating the observed hypersensitivity. C57BL/6 and $\operatorname{Trif}^{d p s 2}$ mice underwent a sham SNL procedure, similar in all respects to the protocol followed for the SNL, except that the L5 spinal nerve was surgically exposed, but 

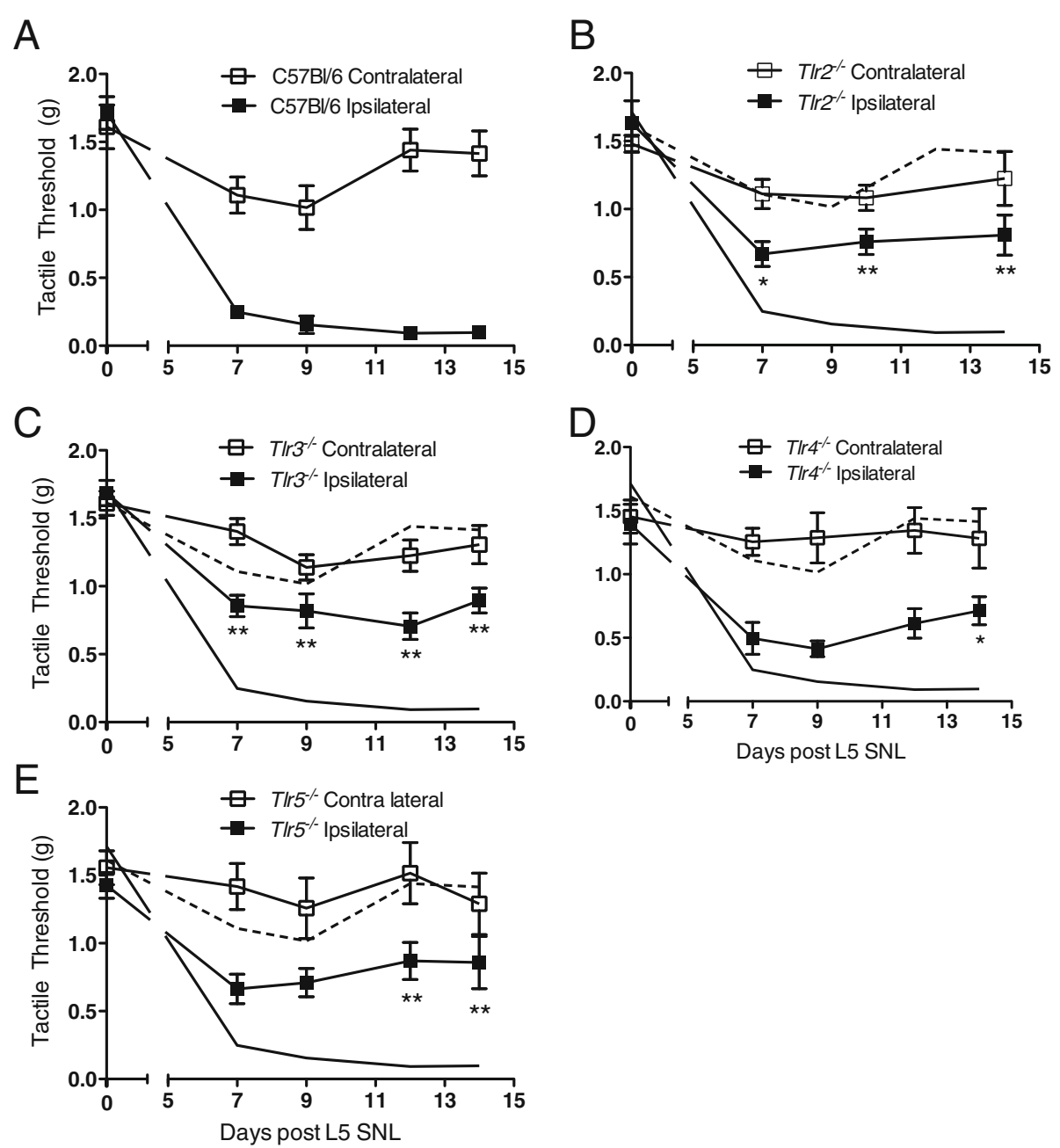

Figure 2 Unilateral tactile allodynia observed following L5 SNL in C57BL/6 mice reduced in TLR signaling deficient mice. $L 5$ SNL waS

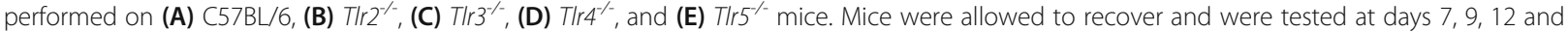
14 post-SNL. The solid black line and dashed line represent the C57BL/6 ipsilateral and contralateral thresholds, respectively, on B-E. (A) C57BL/6 mice show a robust tactile allodynia in the ipsilateral paw beginning 7-days post-surgery. The (B) T/r ${ }^{-\%}$, (C) T/r $3^{\%}$, (D) T/r $4^{\%}$, and (E) T/r $5^{\%}$ all produced a reduction in the ipsilateral paw tactile threshold following L5 SNL, but none completely reversed nerve injury-induced allodynia. Data are expressed as mean \pm SEM ( $n=5-8$ mice/group) and analyzed via 2-way ANOVA, followed by Bonferroni post hoc test to compare each time point to the respective WT $\mathrm{C} 57 \mathrm{BL} / 6$ group, ipsilateral or contralateral $\left({ }^{*} P<0.05\right.$ or $\left.{ }^{* *} P<0.01\right)$.

not ligated. This resulted in no significant change in tactile thresholds following the procedure or any difference between the two mouse strains (Additional file 2: Figure S2).

\section{Dorsal horn glial activation}

Spinal Iba-1 and GFAP have previously been shown to be upregulated in the lumbar spinal cord ipsilateral to the nerve injury in C57BL/6 mice. Lumbar spinal tissue was collected at 14 days post-L5 SNL and incubated with antibodies for both Iba-1 and GFAP. Quantification of both Iba-1 and GFAP show distinct increases in immunoreactivity ipsilateral to the side of injury in laminae
I-III at this time point (Figure 4A,B). There was no significant difference among the C57BL/6 animals and any of the specific TLR deficient animals; representative stained images show this ipsilateral increase (Figure 4C-F,

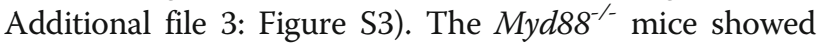
less ipsilateral Iba-1 activation as compared to the C57BL/ 6 ipsilateral activation, while there was no difference in GFAP (Figure 5A,B,E,F). The Trif ${ }^{p s 2}$ mice, which developed both ipsilateral and contralateral tactile allodynia, showed a significant increase in the ipsilateral Iba- 1 activation and a numerical increase in the contralateral Iba-1 immunoreactivity that did not reach statistical significance and no difference in GFAP on either side 


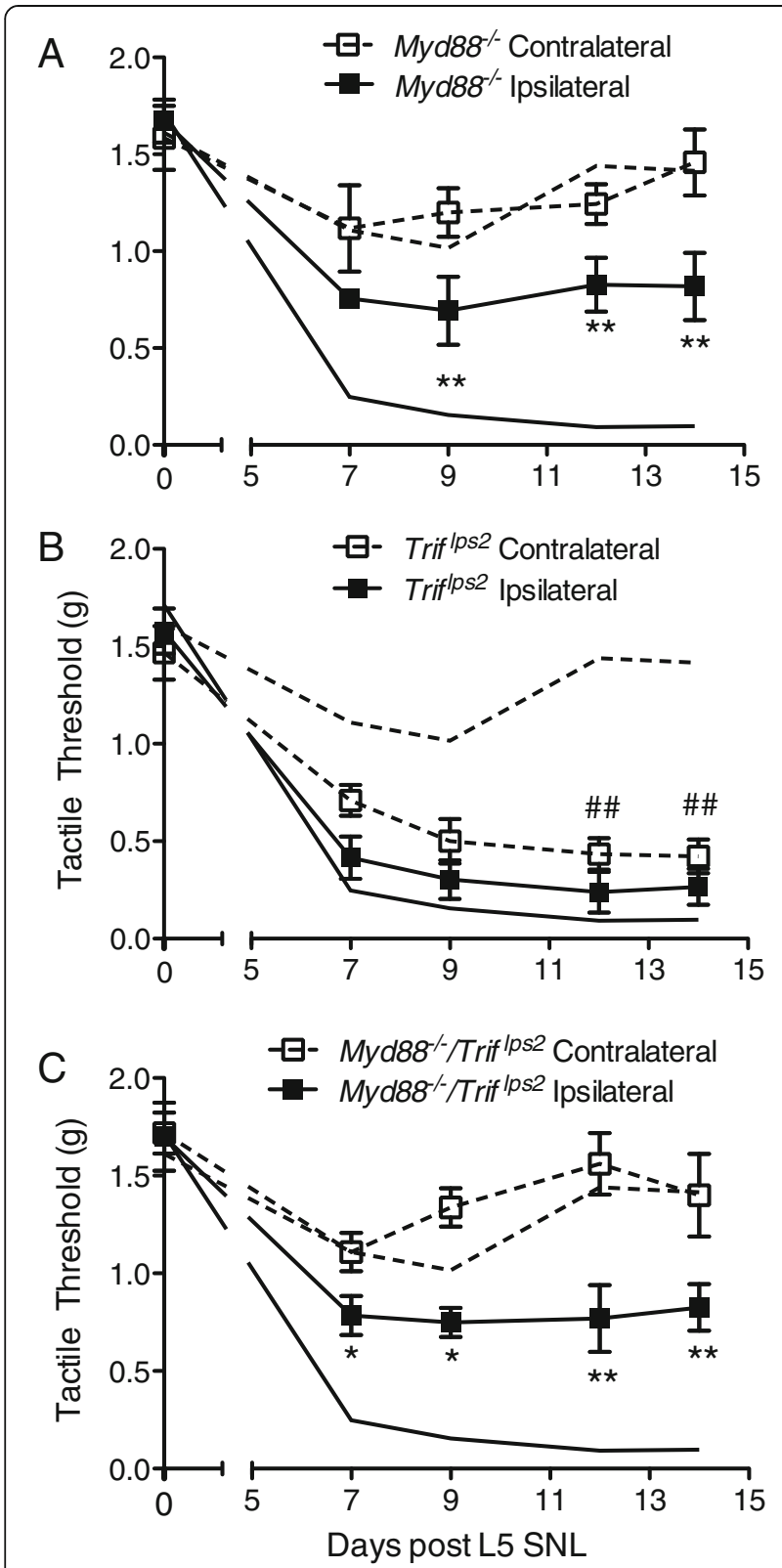

Figure 3 TRIF is important for unilateral tactile allodynia phenotype following L5 SNL. L5 SNL was performed on (A)

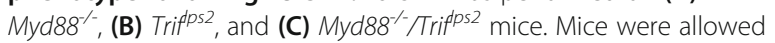
to recover and were tested at days 7, 9, 12, and 14 post-SNL. The solid black line and dashed line represents the C57BL/6 ipsilateral and contralateral thresholds, respectively. Both (A) Myd88 $8^{-1}$ and (C)

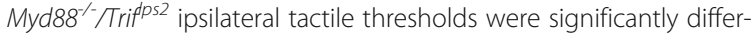
ent from the C57BL/6 thresholds beginning 7 days post-L5 SNL. Surprisingly, the (B) Trif ps2 mice displayed a tactile allodynia in both ipsilateral and contralateral paws. The Trif ${ }^{j p s 2}$ ipsilateral paw thresholds were not significantly different from the C57BL/6 mice, but the contralateral paws were significantly different beginning at day 12 post-L5 SNL. Data are expressed as mean \pm SEM ( $n=5-8$ mice/ group) and analyzed via 2-way ANOVA, followed by Bonferroni post hoc test to compare each time point to the respective C57BL/6 group, ipsilateral or contralateral $\left({ }^{*} P<0.05\right.$ or ${ }^{* *} P<0.01$ for ipsilateral group; \#\#P<0.01 for contralateral group).
(Figure 5A,B,G,H). Representative staining images, which were used for the Iba-1 and GFAP quantification, are shown in Additional file 3: Figure S3.

\section{Dorsal root ganglia ATF3 expression}

To assess the afferent response to nerve injury following SNL, DRGs were incubated with antibodies for ATF3. In the absence of injury, very few C57BL/6 DRGs showed ATF3 expression. However, following surgery, approximately $40 \%$ of the ipsilateral L5 DRG neurons displayed ATF3 positive nuclei (Figure 6A). In the DRGs from Myd88 $8^{-/}$mice, the percent of ATF3-positive DRG neurons fell to around $20 \%$ suggesting that inhibition of MyD88, or all TLR signaling, except TLR3, diminished the consequence of the SNL. The signaling mutation in TRIF did not affect the number of ATF3 positive nuclei (Figure 6A). In the TRIF deficient animals there was also no increase of ATF3 positive nuclei in the contralateral DRGs. Representative stained images are presented with white arrows labeling examples of ATF3 positive nuclei (Figure 6B-J; Additional file 4: Figure S4).

\section{Type I interferon mediates TRIF regulation of contralateral allodynia}

To further delineate the pathway responsible for the contralateral drop in thresholds in the Trif ${ }^{p s s 2}$ mice, we compared two strains deficient in IFN regulatory factors (IRF) that are known TLR signaling regulators. IRF3 is downstream of TRIF (TLR3 and TLR4), and IRF3 signaling deficient mice $\left(\operatorname{Irf3}^{--}\right)$have the same contralateral and ipsilateral allodynia profile following L5 SNL (Figure 7A). This confirmed the effect of the Trif ${ }^{p s s}$ mice previously observed (Figure 3B). TLR7 and TLR9 signaling through MyD88 and IRF7 can also produce type I IFNs, primarily IFN $\alpha$. In $I r f 7^{\prime-}$ mice following L5 SNL, a robust ipsilateral tactile allodynia was observed and the basal contralateral paw threshold was maintained, just as in the C57BL/6 and Myd $88^{-/}$mice (Figure 3A and Figure 7B).

These results indicated that the expression of the contralateral pain phenotype after unilateral nerve injury was regulated by the TRIF-IRF3 pathway. Stimulation of TLRs through MyD88 and TRIF can result in proinflammatory cytokines such as TNF through NF- $\mathrm{kB}$ or type I IFNs via IRF3, respectively. Thus, we looked at the L5 SNL model in mice deficient in TNF and type 1 IFN receptors (Figure $7 \mathrm{C}$ and D). These $\mathrm{Tnf}^{/-}$and Ifnar ${ }^{-1-}$ mice exhibited the same tactile allodynia profile as the mice deficient in MyD88 and TRIF signaling, respectively.

Since $\operatorname{Trif} f^{p s 2}$, $\operatorname{Irf} 3^{-/}$, and Ifnar ${ }^{-1-}$ mice displayed both ipsilateral and contralateral allodynia following SNL, we further hypothesized that IFN $\beta$ could be a regulatory mediator in the nociceptive processing initiated by nerve injury. C57BL/6 mice treated with IFN $\beta$ intrathecally $(100 \mathrm{ng} / 5 \mu \mathrm{L})$ at day 12 post-L5 SNL produced a 


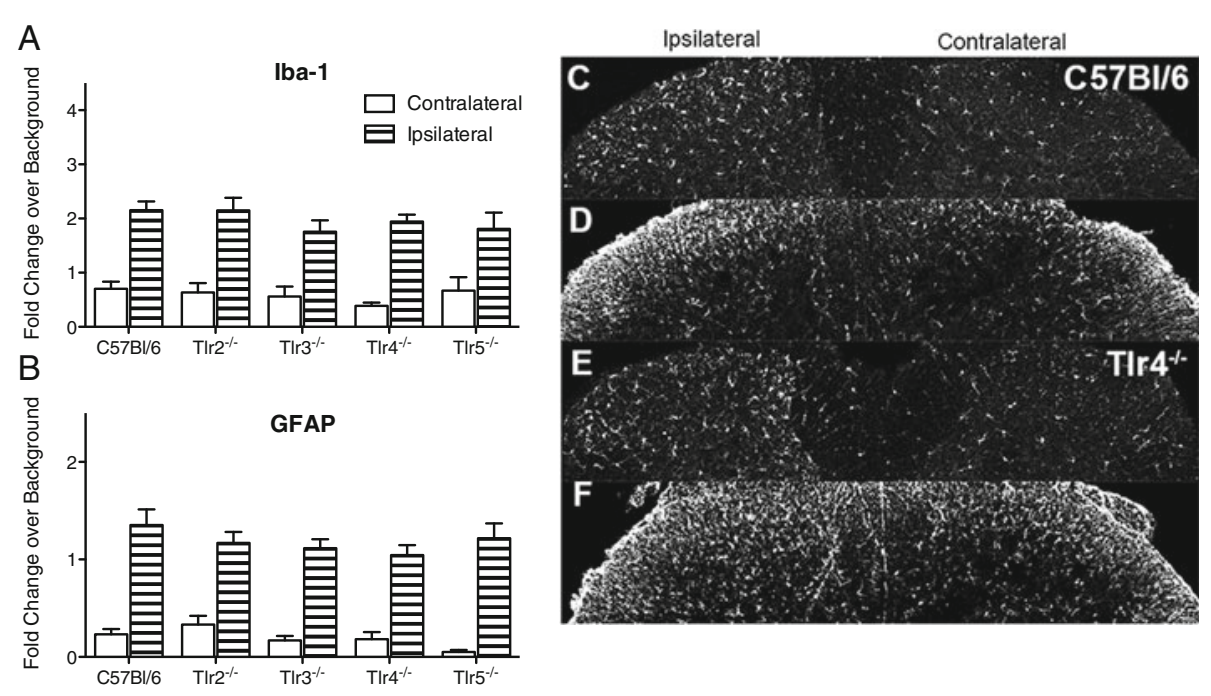

Figure 4 Glial activation in lumbar spinal cord following L5 SNL. At day 14 following L5 SNL, the lumbar region of the spinal cord was harvested and incubated with antibodies against Iba-1 and GFAP. Both (A) Iba-1 and (B) GFAP immunoreactivity is consistently elevated in the ipsilateral side of the dorsal horn compared to contralateral within each group. Data are expressed as mean \pm SEM $(n=3-5$ sections per mouse, with 3-4 mice/group) and analyzed via 2-way ANOVA followed by Bonferroni post hoc test. No differences were found across mouse strains. Representative stained images are presented from C57BL/6 mice with (C) Iba-1 and (D) GFAP staining and from T/r $4^{-1-}$ mice with (E) Iba-1 and (F) GFAP staining.

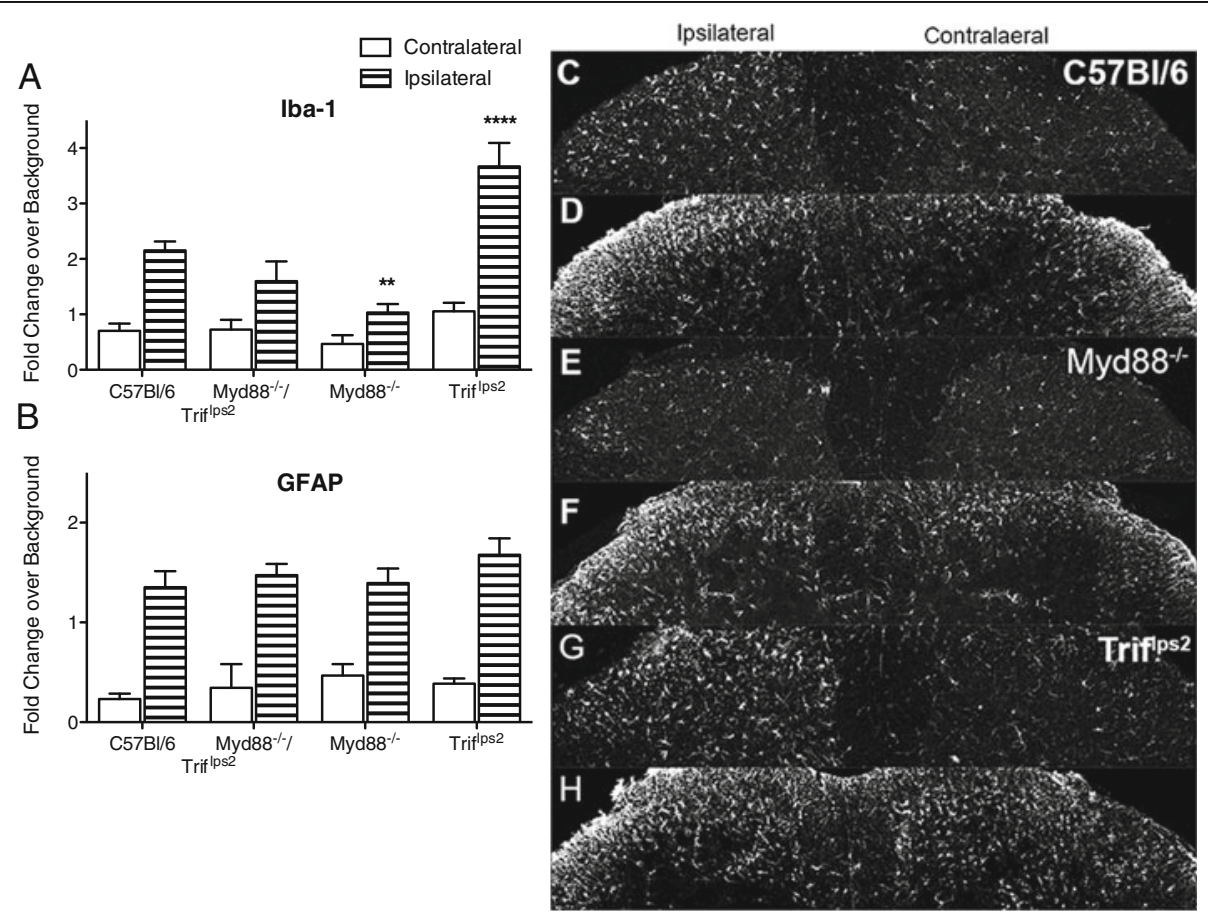

Figure 5 TRIF and MyD88 signaling deficient mice have different lba-1 immunoreactivity profiles following L5 SNL. At day 14 following L5 SNL the lumbar region of the spinal cord was harvested and incubated with antibodies against Iba-1 and GFAP. Both (A) Iba-1 and (B) GFAP immunoreactivity were consistently significantly elevated in the ipsilateral side of the dorsal horn compared to contralateral within each group. Data expressed as mean \pm SEM ( $n=3-5$ sections per mouse, with 3-4 mice/group) and analyzed via 2-way ANOVA followed by Bonferroni post

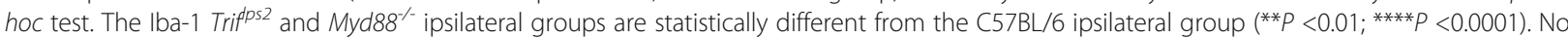
significant difference was found among the contralateral groups. Representative stained images are presented from C57BL/6 mice with (C) Iba-1 and (D) GFAP, Myd88\% mice with (E) Iba-1 and (F) GFAP, and Trif ${ }^{-12}$ mice with (G) Iba-1 and (H) GFAP, which support the quantified immunoreactivity results. 

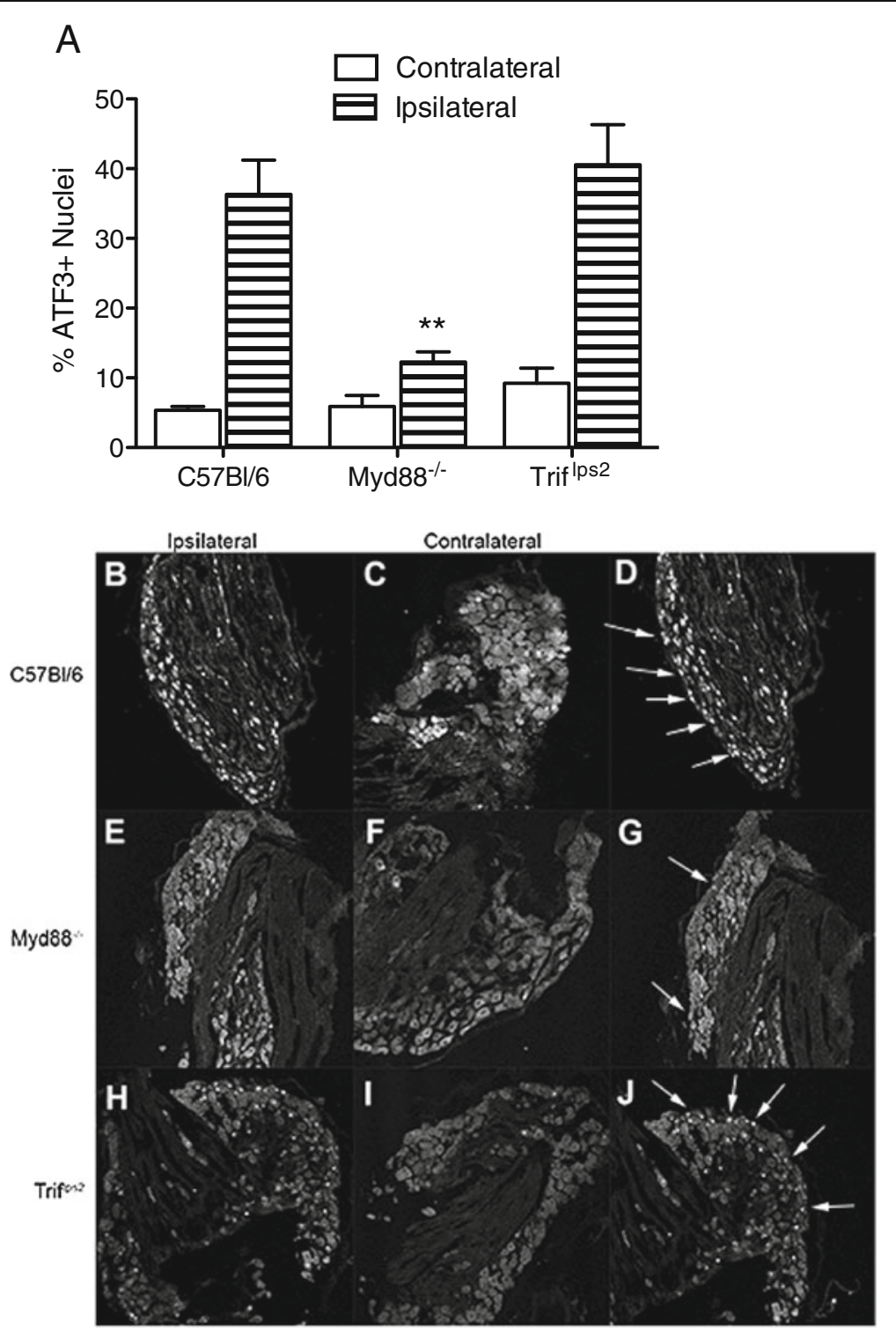

Figure 6 MyD88 signaling deficient mice have less ATF3+ nuclei following L5 SNL. At day 14 following L5 SNL, the ipsilateral and contralateral L5 DRGs were harvested and incubated with an antibody against ATF3. (A) Myd88\% DRGs display less ATF3 immunoreactivity in their L5 ipsilateral DRGs when compared to C57BL/6. No significant difference was found among the other groups. Data expressed as mean \pm SEM ( $n=4-8$ mice/group) and analyzed via 2-way ANOVA followed by Bonferroni post hoc test. The Myd88\% ipsilateral group is statistically different from the C57BL/6 ipsilateral group (**P<0.01). Representative stained images from the DRGs of C57BL/6 (B-D), Myd88 ${ }^{--}$(E-G), and Trif ${ }^{\text {ps2 }}$ (H-J) mice are presented. Examples of ATF3+ nuclei are marked with a white arrow in $\mathbf{D}, \mathbf{G}$, and $\mathbf{J}$.

transient reversal (lasting longer than 4 hours but less than 24 hours) in the L5-SNL-induced tactile allodynia (Figure 8A). When IFN $\beta$ was administered i.p. (7,500 U/ $100 \mu \mathrm{L}$ ), no effect on tactile thresholds was observed (Figure 8B). In other models, IFN $\beta$ is often administered not in a single dose, but as a multi-dose pretreatment. Thus, we gave C57BL/6 mice six doses of IFN $\beta$ i.p. $(7500 \mathrm{U} / 100 \mu \mathrm{L})$ beginning at day 0 , before L5 SNL, and continuing daily through day 7 . This prolonged IFN $\beta$ i.p. treatment regimen also had no effect on tactile thresholds (Additional file 5: Figure S5).

\section{Discussion}

This study examines the role of TLRs and their respective adaptor proteins on tactile allodynia associated with L5 SNL mononeuropathy. There are several pivotal observations:

i) The robust unilateral tactile allodynia initiated by L5 SNL was incompletely reversed in MyD88, or MyD88/TRIF signaling-deficient male mice. These mice displayed only a partial reduction in withdrawal thresholds and slightly reduced ipsilateral Iba-1 
A

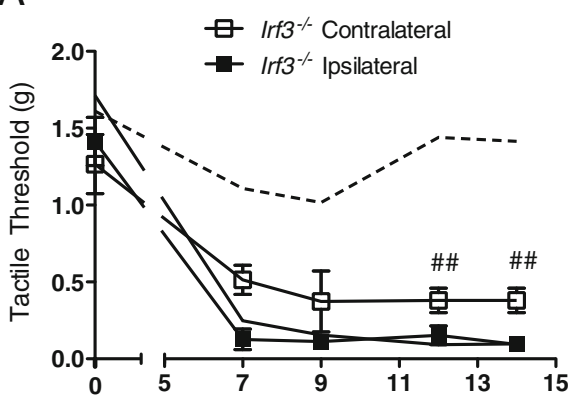

C

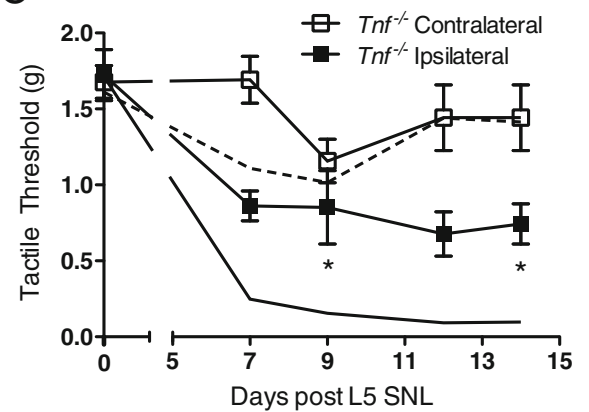

B

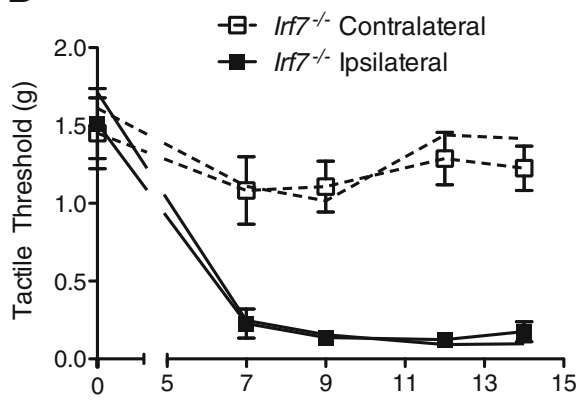

D

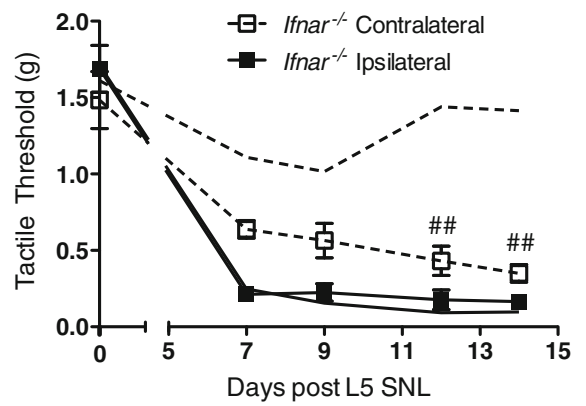

Figure 7 IRF3 and IFNR signaling is required for regulation of contralateral tactile allodynia following L5 SNL. L5 SNL was performed on (A) $\mathrm{IfF}^{-\%}$, and (B) $\mathrm{Iff}^{\circ} /$, (C) $\mathrm{Tnf}^{\circ}$, and (D) Ifnar ${ }^{-/}$mice. Mice were allowed to recover and were tested at days 7, 9, 12, and 14 post-SNL. The solid black line and the dashed line represent the C57BL/6 ipsilateral and contralateral thresholds, respectively. The $/ \mathrm{rf3}^{-1-}$ (A) and Ifnar/- (D) mice displayed a tactile allodynia in both the ipsilateral and contralateral paws. Conversely, the $/ r f 7^{\prime-}$ (B) and $\mathrm{Tnf}^{\prime-}$ (C) mice only produced a drop in the ipsilateral paw threshold. There was no statistical significance between the C57BL/6 mice and these mice. Data expressed as mean \pm SEM ( $n=5-8$ mice/group) and analyzed via 2-way ANOVA, followed by Bonferroni post hoc test to compare each time point to the respective C57BL/ 6 group, ipsilateral or contralateral ( ${ }^{*} P<0.05$ or ${ }^{*} P<0.01$ for ipsilateral group; \#\# $<0.01$ for contralateral group).

immuno-reactivity. This indicates that the partial reduction in tactile allodynia, as compared to C57BL/6 mice, reflects events other than those mediated by TLRs alone. This is consistent with the observation that $T l r 2^{-1}, \mathrm{Tlr}^{-1}, \mathrm{Tlr} 4^{-/}$, and $\mathrm{Tlr} 5^{-/}$mice showed a comparable partial reduction in tactile allodynia, as compared to C57BL/6 mice.

ii) $\mathrm{Tnf}^{\prime-}$ male mice showed only a partial reduction in the L5 SNL-induced tactile allodynia indicating alternate/additional downstream cytokine mediators for tactile allodynia following L5 SNL.

iii) $\operatorname{Trif}^{\text {pps } 2}$ male mice developed profound ipsilateral and contralateral tactile allodynia, suggesting an enhanced response to the L5 SNL. Disruption of MyD88 prevented contralateral tactile allodynia in the Myd $88^{-/} /$Trif $^{p s s 2}$ male mice, suggesting a critical role for the MyD88 pathway in initiating neuropathic pain.

iv) IFN $\beta$ administered intrathecally transiently reversed the L5 SNL, suggesting a distinct role for the TRIF/ IRF3 pathway and interferons in regulating the expression of the neuropathic pain phenotype.

v) In contrast to the male $T l r 4^{-1-}$ mice, the female $T l r 4^{-1-}$ mice did not show a reduction in the observed tactile allodynia following L5 SNL.
The partial effects of L5 SNL on tactile allodynia in $T l r 2^{-/-}$and $T l r 4^{-/-}$male mice are comparable to previous reports $[31,56]$. The lack of TNF signaling diminished, but did not prevent, L5 SNL induced nociception, a finding also comparable to other reports where TNF ablation alone was insufficient to completely inhibit nerve injury-induced allodynia [57]. These results, however, show that MyD88 signaling is required for the development of nerve injury evoked tactile allodynia. Conversely, TRIF is important not only for recovery following nerve injury-induced allodynia, but also in the absence of TRIF signaling a unilateral nerve injury yields an unexpected bilateral effect. This TRIF action in developing neuropathy is mediated at least in part through IFN $\beta$ (Figure 9), suggesting an intrinsic regulatory action upon nerve injuryinduced changes in nociceptive processing.

\section{Spinal TLR signaling and allodynia}

As noted above, we have previously characterized downstream signaling and behavioral effects arising from the activation of spinal TLR2, 3, or 4 [47]. IT delivery of the respective agonists evoked a robust and persistent tactile allodynia by a specific action on their respective TLRs. Consistent with their downstream signaling cascade 


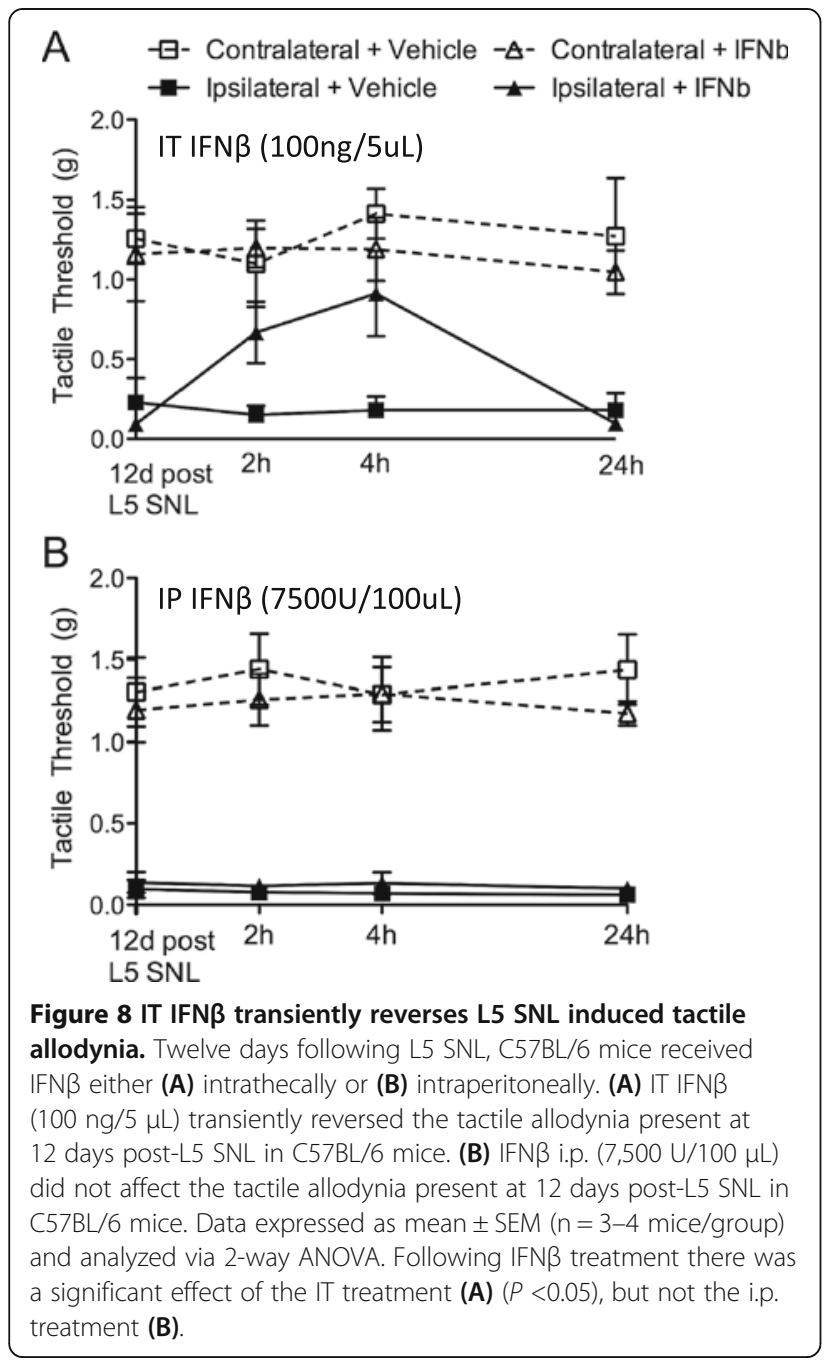

(Figure 1A), in TIRAP signaling-deficient mice (downstream to TLR2 and TLR4), allodynia after IT TLR2 ligand and TLR4 ligand was abolished. Unexpectedly, however, in TRIF $\left(T_{r i f}{ }^{p s 2}\right.$ ) signaling-deficient mice (downstream of TLR3 and TLR4), TLR3 mediated tactile allodynia was abolished, but spinal TLR4 activation produced an unexpectedly persistent and robust enhancement ( $>21$ days) in tactile allodynia. Consistent with a role of IFN $\beta$ (downstream to TRIF) in regulating recovery after IT TLR4 ligand, a persistent tactile allodynia was also noted in IFN signaling-deficient mice. Additionally, through the use of Tnf ${ }^{\prime-}$ mice, we noted that spinal TIRAP and TRIF cascades differentially lead to robust tactile allodynia by TNF-dependent and -independent pathways, respectively.

We believe that these previous studies provide a mechanistic framework for interpreting the results observed in the SNL mononeuropathy-mediated tactile allodynia. Thus, we emphasize the following: i) disruption of TRIF/IFN signaling leads to an enhanced and prolonged spinal response, suggesting that the TRIF

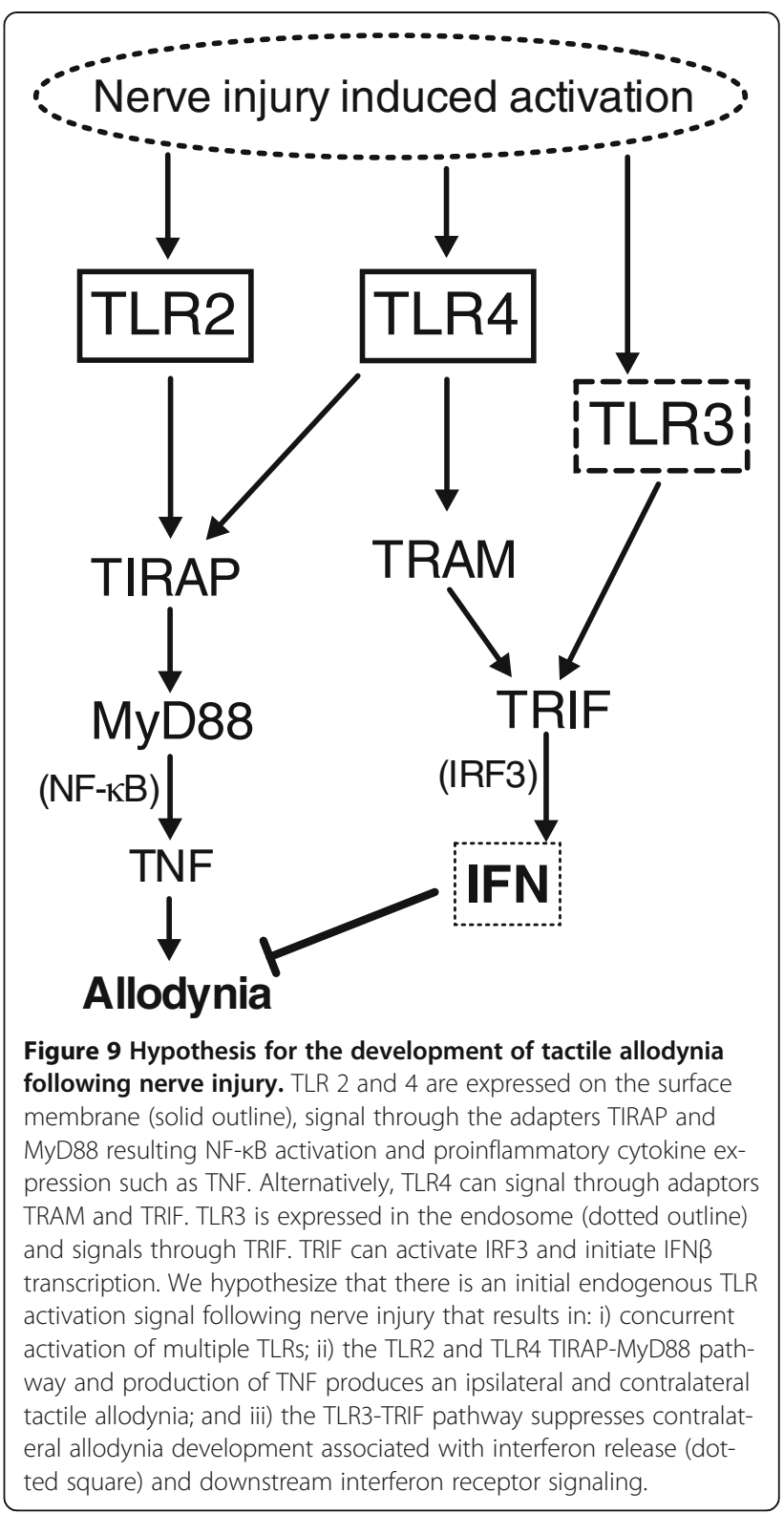

pathway is involved in the recovery following nerve injury; ii) disruption of MyD88 signaling blocked the effects of the respective TLRs, completely preventing contralateral tactile allodynia in the $M y d 88^{-/} / \operatorname{Trif}^{d p s 2}$ mice; thus, MyD88 is required for contralateral tactile allodynia to develop; and, iii) IT IFN $\beta$ indeed produced a transient reversal of the observed L5 SNL-induced tactile allodynia.

\section{Contralateral allodynia and unilateral nerve injury}

The development of a bilateral effect as a result of MyD88 signaling in the male Trif $f^{p s 2}$ mice is of particular interest. While the common mononeuropathy pain phenotype in humans and in experimental animal models is an ipsilateral change in sensitivity and dysesthesia, contralateral 
(bilateral) effects have been described. Such bilateral expression has been noted in the earliest clinical reports [58-65]. In preclinical models, examples of peripheral mononeuropathy producing contralateral effects are primarily limited to the homotopic contralateral segments $[58,66,67]$. Thus, chronic unilateral compression of the L4 and L5 DRGs in mice produced a strong mechanical and thermal hyperalgesia, as well as tactile allodynia in the ipsilateral paw, which has been reported to spread to the contralateral regions along the same time course [68]. In a rat model of chronic post-cast pain, two-week immobilization due to casting resulted in induced atrophy and inflammatory changes and widespread hyperalgesia that lasted 5 to 10 weeks after cast removal [69].

The mechanism of this onset of bilaterality is not known. As noted, in these studies, the homolaterality excludes a systemic humoral signal. In a model of unilateral intraplantar capsaicin, the c-fos activation pattern of spinal glycineric and GABAergic neurons increased on the opposite spinal relative to the injection [70]. Following unilateral nerve ligation there was a long lasting loss of PGP9 $.5^{+}$cutaneous innervation contralaterally to the unilateral nerve injury, suggesting that transcellular signals link homologous neurons on opposite sides of the body [58]. Alternatively, such bilateral actions may reflect the aberrant activation of the bulbospinal facilitator pathways [71,72]. In the present study, the absence of an increase in ATF3, however, suggests that there was no bilateral effect on afferent nerve integrity. The present studies offer an important potential underlying mechanism. Here, we show that $\operatorname{Trif}^{d p s 2}$ mice developed strong contralateral allodynia while $M y d 88^{-/-} / T_{r i f} f^{p s 2}$ mice only developed ipsilateral allodynia, indicating that MyD88 is required for contralateral allodynia to develop. These results offer the provocative hypothesis that following unilateral nerve injury a bilateral effect mediated by several mechanisms may be the normal occurrence, in the absence of a TRIF-IFN dependent inhibition.

Since both $T r i f^{p s s}$ and Ifnar ${ }^{-/-}$male mice produced both ipsilateral and contralateral allodynia, we hypothesize that type I IFN could play a major role in endogenous pain management following nerve injury. Other reports support this hypothesis since IFN $\beta$ induces MHC class I leading to enhanced axonal growth and motor function recovery following nerve injury [73]. C57BL/6 mice were treated with IT IFN $\beta$ at day 12 post-L5 SNL, which transiently reversed tactile allodynia. However, here, i.p. IFN $\beta$ treatment in both single dose and repetitive doses over 6 days early in the time course, did not improve the tactile thresholds.

\section{Role for endogenous ligands in nerve injury-induced allodynia}

These studies display the complex cascades activated by nerve injury and reveal the likely role of endogenous ligands for the TLRs, which would be present in the DRG and spinal cord secondary to signaling generated by an injury of the peripheral axon in male mice. Products potentially released by neuraxial cells include high mobility group box 1 (HMGB1), tenacin C, peroxiredoxin (Prx) family proteins, $\beta$-amyloid (A $\beta$ ), hyaluronan, DNA or RNA immune complexes, heat shock proteins, and heparan sulfate [74-83]. An intriguing hypothesis is that, in addition to spinal glia and neurons, non-neuronal cells such as macrophages, which migrate into the spinal cord and DRG after peripheral nerve injury, could serve as one source of such neuraxial TLR activation [7].

An interesting observation was that after L5 SNL in C57BL/6 mice, the ipsilateral L5 DRG shows nearly $40 \%$ ATF3 positive nuclei. The DRG from $M y d 88^{-/}$mice showed only around $20 \%$ of ATF3 positive nuclei, suggesting that inhibition of MyD88, results in less DRG reactivity to the nerve injury. TNF, TRIF, or IFNR knockout alone did not affect the number of ATF3 positive nuclei. In terms of nerve injury recovery, the TRIF protein has been implicated in the activation of microglia and p38 MAPK to clear axonal debris following peripheral insult $[84,85]$. This would suggest that without the TRIF protein there would be more axonal debris present with the ability to activate local TLRs, which detect endogenous materials. More specifically, products such as HMGB1, Prx proteins, and other damage-associated molecular pattern molecules previously mentioned, can stimulate TLR2 and TLR4 $[80,86]$. It is important to emphasize that while the TLRs play a defined role in the inflammatory and injuryinitiated components of the classical innate immune response, the research outlined here and elsewhere emphasizes that these TLR cascades play a role in the normal processing of sensory information generated by distant injury and inflammation.

\section{Sex}

In the present work, the primary model examined the role of TLR receptors and adaptor proteins in the male mouse. As reviewed above, an evident role for the TLR cascade in this nerve injury induced allodynia was noted. Sorge et al. [41] reported that in female mice, knockout of TLR4 had no effect on mononeuropathic allodynia. In the present work, female Tlr $4^{-/}$mice also continued to display a robust tactile allodynia following nerve injury. Accordingly, these results are in agreement with those reported previously. Additional studies will be required to consider the role of other TLR cascades in the postnerve injury pain state and whether or not this effect is observed in models of both poly- and mono-neuropathy. Additionally, Sorge et al. [41] reported that spinal TLR4 binding sites were unaltered. This finding suggests several possible alternatives, including the lack of release of endogenous TLR4 agonists. However, the fact that Sorge 
et al. [41] reported that IT Lipopolysaccharide (LPS) had no pro-allodynic effect in the female mice (in contrast to the male) argues against the simple explanation that endogenous agents initiating a hyperpathic state through the TLR4 after nerve ligation were absent in the female. Future work addressing these sex differences for other TLR components will be of considerable interest. Until that time, it is necessary to explicitly note that the present results (and that of others in the area) apply to the male sex, until otherwise shown.

\section{Conclusions}

The present studies uncovered three important roles of the TLR pathway in mononeuropathy in the male mouse: i) individual TLRs only modestly contribute to the allodynia present after nerve injury; ii) TRIF plays a dual role mediating allodynia arising from TLR3 activation and regulating, through an IFN $\beta$ pathway, the recovery following nerve injury-induced allodynia; and iii) the MyD88 pathway is required for the development of contralateral allodynia. Characterization of the agents activating these TLRs and the parameters governing their release will be of particular interest in defining the role of TLRs in nociceptive processing as illustrated by these studies. The roles of these cascades in the female mouse remain to be determined.

\section{Additional files}

Additional file 1: Figure S1. Unilateral TA observed following $L 5$ SNL in C57BL/6 female mice was not reduced in TLR4 signaling-deficient female mice. L5 SNL was performed on female (A) C57BL/6 and (B) Trr $4^{-1}$ mice. Mice were allowed to recover and were tested at days 7, 9, 12, and 14 post-SNL. The solid black line and dashed line represent the C57BL/6 ipsilateral and contralateral thresholds. (A) C57BL/6 mice showed a robust TA in the ipsilateral paw beginning 7 days post-surgery. The (B) T/r $4^{-1}$ mice showed no effect upon the ipsilateral paw tactile threshold following L5 SNL. Data are expressed as mean \pm SEM ( $n=5$ mice/group) and analyzed via 2-way ANOVA, followed by Bonferroni post hoc test to compare each time point to the respective WT C57BL/6 group, ipsilateral or contralateral (\#\#\#> <0.01 vs. contralateral paw; ***post vs. baseline).

Additional file 2: Figure S2. $L 5$ SNL Sham produced no significant effect on tactile thresholds. C57BL/6 and Tritps2 mice underwent L5 SNL sham surgery and tactile thresholds were measured. There were no significant differences between the tactile thresholds of the four groups as assessed by 1-way ANOVA.

Additional file 3: Figure S3. Iba-1 and GFAP immunoreactivity following L5 SNL. At day 14 following L5 SNL, the lumbar region of the spinal cord was harvested and incubated with antibodies against Iba-1 and GFAP. Iba-1 immunoreactivity is visualized with Alexa-488 (green) in the left panel and GFAP with Alexa-594 (red) in the right panel. Quantification for the Iba-1 and GFAP immuno-reactivity is found in Figure 3 and Figure 5.

Additional file 4: Figure S4. ATF3 immuno-reactivity following L5 SNL. At day 14 following L5 SNL, the L5 right and left DRGs were harvested and incubated with an antibody against ATF3. ATF3 immuno-reactivity is visualized with Alexa-488 (green) and recognized as an intense fluorescent mark in the nuclei region. The white arrows point to examples of ATF3 staining. Quantification for the ATF3 immuno-reactivity is found in Figure 6.
Additional file 5: Figure S5. Repetitive treatment with IP IFN $\beta$ had no effect on tactile thresholds following L5 SNL. C57BL/6 mice received i.p. IFNB $(7,500 \mathrm{U} / 100 \mu \mathrm{L})$ or vehicle $(0.1 \% \mathrm{BSA})$ as a pre-treatment on day 0 (before L5 SNL) and days 2, 3, 4, 5, and 6 after L5 SNL. Tactile thresholds were measured on days $7,9,12$, and 14 . No significant differences were found between the i.p. vehicle and i.p. IFN $\beta$ groups as assessed by 2-way ANOVA followed by Bonferroni post-hoc test.

\section{Abbreviations}

ATF3: Activating transcription factor 3; AB: $\beta$-amyloid; DAMP: Damageassociated molecular pattern molecules; DRG: Dorsal root ganglia; HMGB1: High mobility group box 1; IFN: Interferon; LL: Interleukin; IRF: Interferon regulatory factor; IT: Intrathecal; LPS: Lipopolysaccharide; MyD88: Myeloid differentiation primary response gene (88); Prx: Peroxiredoxin; SNL: Spinal nerve ligation; TIRAP: Toll-interleukin 1 receptor (TIR) domain containing adaptor protein; TRIF-TIR: Domaincontaining adapter-inducing interferon- $\beta$; TLR: Toll-like receptor; TNF: Tumor necrosis factor.

\section{Competing interests}

The authors are employees of the University of California, San Diego, and the work was supported by the $\mathrm{NIH}$ grants listed. The authors have no other relevant affiliations or financial involvement with any organization or entity with a financial interest in or financial conflict with the subject matter or materials discussed in the manuscript. This includes employment, consultancies, honoraria, stock ownership or options, expert testimony, grants or patents received or pending, or royalties.

\section{Authors' contributions}

JS and KE performed the SNL and animal testing. JS performed the immunohistochemistry, quantification, and statistics. MC bred and genotyped the mice. JC assisted in the quantification of the immunohistochemistry. JS, MC, and TY conceived of the study, participated in its design and coordination, and helped to draft the manuscript. All authors read and approved the final manuscript.

\section{Acknowledgements}

This work was supported by grants from National Institutes of Health: AR062236, NS16541, DA02110 (TLY/MPC), and T32 GM007752-31 (JAS). The content is solely the responsibility of the authors and does not necessarily represent the official views of the National Institutes of Health.

\section{Author details}

'Department of Pharmacology, University of California, 9500 Gilman Dr. MC 0636, La Jolla, San Diego, CA 92093-0636, USA. ${ }^{2}$ Department of Anesthesiology, University of California, 9500 Gilman Dr. MC 0818, La Jolla, San Diego, CA 92093-0818, USA. ${ }^{3}$ Division of Rheumatology, Allergy and Immunology, University of California, 9500 Gilman Dr. MC 0663, La Jolla, San Diego, CA 92093-0663, USA.

Received: 20 March 2013 Accepted: 18 November 2013

Published: 9 December 2013

\section{References}

1. Marchand F, Perretti M, McMahon SB: Role of the immune system in chronic pain. Nat Rev Neurosci 2005, 6:521-532.

2. Jaggi AS, Jain V, Singh N: Animal models of neuropathic pain. Fund Clin Pharmacol 2011, 25:1-28.

3. Chung JM, Kim HK, Chung K: Segmental spinal nerve ligation model of neuropathic pain. Metho Mol Med 2004, 99:35-45.

4. Saade NE, Jabbur SJ: Nociceptive behavior in animal models for peripheral neuropathy: spinal and supraspinal mechanisms. Progr Neurobiol 2008, 86:22-47.

5. King T, Vera-Portocarrero L, Gutierrez T, Vanderah TW, Dussor G, Lai J, Fields $\mathrm{HL}$, Porreca F: Unmasking the tonic-aversive state in neuropathic pain. Nat Neurosci 2009, 12:1364-1366.

6. Wen YR, Suter MR, Kawasaki Y, Huang J, Pertin M, Kohno T, Berde CB, Decosterd I, Ji RR: Nerve conduction blockade in the sciatic nerve prevents but does not reverse the activation of p38 mitogen-activated 
protein kinase in spinal microglia in the rat spared nerve injury model. Anesthesiology 2007, 107:312-321.

7. Calvo M, Bennett DL: The mechanisms of microgliosis and pain following peripheral nerve injury. Exp Neurol 2012, 234:271-282.

8. Hashizume H, DeLeo JA, Colburn RW, Weinstein JN: Spinal glial activation and cytokine expression after lumbar root injury in the rat. Spine 2000, 25:1206-1217.

9. Cao H, Zhang YQ: Spinal glial activation contributes to pathological pain states. Neurosci Biobehav Rev 2008, 32:972-983.

10. Guo LH, Schluesener HJ: The innate immunity of the central nervous system in chronic pain: the role of toll-like receptors. Cell Mol Life Sci 2007, 64:1128-1136.

11. Hu P, Bembrick AL, Keay KA, McLachlan EM: Immune cell involvement in dorsal root ganglia and spinal cord after chronic constriction or transection of the rat sciatic nerve. Brain Behav Immun 2007, 21:599-616

12. Hu P, McLachlan EM: Macrophage and lymphocyte invasion of dorsal root ganglia after peripheral nerve lesions in the rat. Neuroscience 2002, 112:23-38.

13. Kim CF, Moalem-Taylor G: Detailed characterization of neuro-immune responses following neuropathic injury in mice. Brain Res 2011, 1405:95-108.

14. Wang R, Guo W, Ossipov MH, Vanderah TW, Porreca F, Lai J: Glial cell linederived neurotrophic factor normalizes neurochemical changes in injured dorsal root ganglion neurons and prevents the expression of experimental neuropathic pain. Neuroscience 2003, 121:815-824.

15. Tsujino H, Kondo E, Fukuoka T, Dai Y, Tokunaga A, Miki K, Yonenobu K, Ochi T, Noguchi K: Activating transcription factor 3 (ATF3) induction by axotomy in sensory and motoneurons: a novel neuronal marker of nerve injury. Mol Cell Neurosci 2000, 15:170-182.

16. Znaor L, Lovric S, Hogan Q, Sapunar D: Association of neural inflammation with hyperalgesia following spinal nerve ligation. Croatian Med J 2007 , 48:35-42.

17. Panagio LA, Tristao FS, Moreira AP, Pereira MS, Cavassani KA, Milanezi CM, Rossi MA, Silva JS: Role of interleukin (IL)-18 in experimental paracoccidioidomycosis. Med Mycol 2008, 46:435-442.

18. Hua XY, Svensson Cl, Matsui T, Fitzsimmons B, Yaksh TL, Webb M: Intrathecal minocycline attenuates peripheral inflammation-induced hyperalgesia by inhibiting p38 MAPK in spinal microglia. Eur J Neurosci 2005, 22:2431-2440.

19. Mika J, Osikowicz M, Makuch W, Przewlocka B: Minocycline and pentoxifylline attenuate allodynia and hyperalgesia and potentiate the effects of morphine in rat and mouse models of neuropathic pain. Eur Pharmacol 2007, 560:142-149.

20. Raghavendra V, Tanga F, Rutkowski MD, DeLeo JA: Anti-hyperalgesic and morphine-sparing actions of propentofylline following peripheral nerve injury in rats: mechanistic implications of spinal glia and proinflammatory cytokines. Pain 2003, 104:655-664.

21. Saito O, Svensson Cl, Buczynski MW, Wegner K, Hua XY, Codeluppi S, Schaloske RH, Deems RA, Dennis EA, Yaksh TL: Spinal glial TLR4-mediated nociception and production of prostaglandin $\mathrm{E}(2)$ and TNF. Br J Pharmacol 2010, 160:1754-1764.

22. Pu S, Xu Y, Du D, Yang M, Zhang X, Wu J, Jiang W: Minocycline attenuates mechanical allodynia and expression of spinal NMDA receptor 1 subunit in rat neuropathic pain model. J Physiol Biochem 2013, 69(3):349-357.

23. Akira S: Toll-like receptor signaling. J Biol Chem 2003, 278:38105-38108.

24. Akira S, Sato S: Toll-like receptors and their signaling mechanisms. Scand J Infect Dis 2003, 35(9):555-562.

25. Bsibsi M, Ravid R, Gveric D, van Noort JM: Broad expression of toll-like receptors in the human central nervous system. J Neuropathol Exp Neurol 2002, 61:1013-1021.

26. Bowman CC, Rasley A, Tranguch SL, Marriott I: Cultured astrocytes express toll-like receptors for bacterial products. Glia 2003, 43:281-291.

27. Jack CS, Arbour N, Manusow J, Montgrain V, Blain M, McCrea E, Shapiro A, Antel JP: TLR signaling tailors innate immune responses in human microglia and astrocytes. J Immunol 2005, 175:4320-4330.

28. Ledeboer A, Sloane EM, Milligan ED, Frank MG, Mahony JH, Maier SF, Watkins LR: Minocycline attenuates mechanical allodynia and proinflammatory cytokine expression in rat models of pain facilitation. Pain 2005, 115:71-83.

29. Raghavendra V, Tanga F, DeLeo JA: Inhibition of microglial activation attenuates the development but not existing hypersensitivity in a rat model of neuropathy. J Pharmacol Exp Therapeut 2003, 306:624-630.
30. Lehnardt S: Innate immunity and neuroinflammation in the CNS: the role of microglia in toll-like receptor-mediated neuronal injury. Glia 2010, 58:253-263

31. Kim D, Kim MA, Cho IH, Kim MS, Lee S, Jo EK, Choi SY, Park K, Kim JS, Akira $\mathrm{S}, \mathrm{Na} \mathrm{HS}$, Oh SB, Lee SJ: A critical role of toll-like receptor 2 in nerve injury-induced spinal cord glial cell activation and pain hypersensitivity. J Biol Chem 2007, 282:14975-14983.

32. Kim D, Lee $\mathrm{S}$, Lee SJ: Toll-like receptors in peripheral nerve injury and neuropathic pain. Curr Top Microbiol Immunol 2009, 336:169-186.

33. Hutchinson MR, Ramos KM, Loram LC, Wieseler J, Sholar PW, Kearney JJ, Lewis MT, Crysdale NY, Zhang Y, Harrison JA, Maier SF, Rice KC, Watkins LR: Evidence for a role of heat shock protein-90 in toll like receptor 4 mediated pain enhancement in rats. Neuroscience 2009, 164:1821-1832.

34. Cao L, Tanga FY, Deleo JA: The contributing role of CD14 in toll-like receptor 4 dependent neuropathic pain. Neuroscience 2009, 158:896-903.

35. Nicotra L, Loram LC, Watkins LR, Hutchinson MR: Toll-like receptors in chronic pain. Exp Neurol 2012, 234:316-329.

36. Stokes JA, Corr M, Yaksh TL: Transient tactile allodynia following intrathecal puncture in mouse: contributions of toll-like receptor signaling. Neurosci Lett 2011, 504:215-218.

37. Christianson CA, Dumlao DS, Stokes JA, Dennis EA, Svensson Cl, Corr M, Yaksh TL: Spinal TLR4 mediates the transition to a persistent mechanical hypersensitivity after the resolution of inflammation in serumtransferred arthritis. Pain 2011, 152:2881-2891.

38. DeLeo JA, Yezierski RP: The role of neuroinflammation and neuroimmune activation in persistent pain. Pain 2001, 90:1-6.

39. Xu Q, Yaksh TL: A brief comparison of the pathophysiology of inflammatory versus neuropathic pain. Curr Opin Anaesthesiol 2011, 24:400-407.

40. Tanga FY, Nutile-McMenemy N, DeLeo JA: The CNS role of toll-like receptor 4 in innate neuroimmunity and painful neuropathy. Proc Natl Acad Sci USA 2005, 102:5856-5861.

41. Sorge RE, LaCroix-Fralish ML, Tuttle AH, Sotocinal SG, Austin JS, Ritchie J, Chanda ML, Graham AC, Topham L, Beggs S, Salter MW, Mogil JS: Spinal cord toll-like receptor 4 mediates inflammatory and neuropathic hypersensitivity in male but not female mice. J Neurosci 2011, 31:15450-15454.

42. Bettoni I, Comelli F, Rossini C, Granucci F, Giagnoni G, Peri F, Costa B: Glial TLR4 receptor as new target to treat neuropathic pain: efficacy of a new receptor antagonist in a model of peripheral nerve injury in mice. Glia 2008, 56:1312-1319.

43. Kawai T, Akira S: TLR signaling. Cell Death Differ 2006, 13:816-825.

44. Yamamoto M, Sato S, Mori K, Hoshino K, Takeuchi O, Takeda K, Akira S: Cutting edge: a novel toll//L-1 receptor domain-containing adapter that preferentially activates the IFN-beta promoter in the toll-like receptor signaling. J Immunol 2002, 169:6668-6672.

45. Hacker H, Redecke V, Blagoev B, Kratchmarova I, Hsu LC, Wang GG, Kamps MP, Raz E, Wagner H, Hacker G, Mann M, Karin M: Specificity in toll-like receptor signalling through distinct effector functions of TRAF3 and TRAF6. Nature 2006, 439:204-207.

46. O'Neill LA, Bowie AG: The family of five: TIR-domain-containing adaptors in toll-like receptor signalling. Nat Rev Immunol 2007, 7:353-364.

47. Stokes JA, Corr M, Yaksh TL: Spinal toll-like receptor signaling and nociceptive processing: regulatory balance between TIRAP and TRIF cascades mediated by TNF and IFNbeta. Pain 2013, 154(5):733-742.

48. Adachi O, Kawai T, Takeda K, Matsumoto M, Tsutsui H, Sakagami M, Nakanishi K, Akira S: Targeted disruption of the MyD88 gene results in loss of IL-1- and IL-18-mediated function. Immunity 1998, 9:143-150.

49. Hoshino K, Takeuchi O, Kawai T, Sanjo H, Ogawa T, Takeda Y, Takeda K, Akira S: Cutting edge: toll-like receptor 4 (TLR4)-deficient mice are hyporesponsive to lipopolysaccharide: evidence for TLR4 as the Lps gene product. J Immunol 1999, 162:3749-3752.

50. Takeuchi O, Hoshino K, Kawai T, Sanjo H, Takada H, Ogawa T, Takeda K, Akira S: Differential roles of TLR2 and TLR4 in recognition of gramnegative and gram-positive bacterial cell wall components. Immunity 1999, 11:443-451.

51. Hoebe K, Du X, Georgel P, Janssen E, Tabeta K, Kim SO, Goode J, Lin P, Mann N, Mudd S, Crozat K, Sovath S, Han J, Beutler B: Identification of Lps2 as a key transducer of MyD88-independent TIR signalling. Nature 2003, 424:743-748.

52. Sakaguchi S, Negishi H, Asagiri M, Nakajima C, Mizutani T, Takaoka A, Honda $\mathrm{K}$, Taniguchi T: Essential role of IRF-3 in lipopolysaccharide-induced 
interferon-beta gene expression and endotoxin shock. Biochem Biophys Res Comm 2003, 306:860-866.

53. Honda K, Yanai H, Negishi H, Asagiri M, Sato M, Mizutani T, Shimada N, Ohba Y, Takaoka A, Yoshida N, Taniguchi T: IRF-7 is the master regulator of type-I interferon-dependent immune responses. Nature 2005, 434:772-777.

54. Chaplan SR, Bach FW, Pogrel JW, Chung JM, Yaksh TL: Quantitative assessment of tactile allodynia in the rat paw. J Neurosci Meth 1994, 53:55-63.

55. Hylden $J \mathrm{~L}$, Wilcox $\mathrm{GL}$ : Intrathecal morphine in mice: a new technique. Eur J Pharmacol 1980, 67:313-316.

56. Hutchinson MR, Zhang Y, Brown K, Coats BD, Shridhar M, Sholar PW, Patel SJ, Crysdale NY, Harrison JA, Maier SF, Rice KC, Watkins LR: Nonstereoselective reversal of neuropathic pain by naloxone and naltrexone: involvement of toll-like receptor 4 (TLR4). Eur J Neurosci 2008, 28:20-29.

57. Nadeau S, Filali M, Zhang J, Kerr BJ, Rivest S, Soulet D, Iwakura Y, de Rivero Vaccari JP, Keane RW, Lacroix S: Functional recovery after peripheral nerve injury is dependent on the pro-inflammatory cytokines IL-1 beta and TNF: implications for neuropathic pain. J Neurosci 2011, 31:12533-12542.

58. Oaklander AL, Brown JM: Unilateral nerve injury produces bilateral loss of distal innervation. Ann Neurol 2004, 55:639-644.

59. Kozin F, Genant HK, Bekerman C, McCarty DJ: The reflex sympathetic dystrophy syndrome. II. Roentgenographic and scintigraphic evidence of bilaterality and of periarticular accentuation. Am J Med 1976, 60:332-338.

60. Huge V, Lauchart M, Forderreuther S, Kaufhold W, Valet M, Azad SC, Beyer A, Magerl W: Interaction of hyperalgesia and sensory loss in complex regional pain syndrome type I (CRPS I). PloS one 2008, 3:e2742.

61. Konopka KH, Harbers M, Houghton A, Kortekaas R, van Vliet A, Timmerman W, den Boer JA, Struys MM, van Wijhe M: Bilateral sensory abnormalities in patients with unilateral neuropathic pain; a quantitative sensory testing (QST) study. PloS one 2012, 7:e37524.

62. Fernandez-de-las-Penas C, de la Llave-Rincon Al, Fernandez-Carnero J, Cuadrado ML, Arendt-Nielsen L, Pareja JA: Bilateral widespread mechanical pain sensitivity in carpal tunnel syndrome: evidence of central processing in unilateral neuropathy. Brain 2009, 132:1472-1479.

63. de la Llave-Rincon Al, Fernandez-de-las-Penas C, Fernandez-Carnero J, Padua L, Arendt-Nielsen L, Pareja JA: Bilateral hand/wrist heat and cold hyperalgesia, but not hypoesthesia, in unilateral carpal tunnel syndrome. Exp Brain Res Exp Hirnforsch Exp Cerebrale 2009, 198:455-463.

64. Fernandez-de-las-Penas C, Galán-del-Río F, Ortega-Santiago R, Jiménez-García R, Arendt-Nielsen L, Svensson P: Bilateral thermal hyperalgesia in trigeminal and extra-trigeminal regions in patients with myofascial temporomandibular disorders. Exp Brain Res 2010, 202(1):171-179.

65. Mitchell SW: Injuries of nerves and their consequences. Philadelphia: J.B Lippincott; 1872

66. Koltzenburg M, Wall PD, McMahon SB: Does the right side know what the left is doing? Trends Neurosci 1999, 22:122-127.

67. Chacur M, Milligan ED, Gazda LS, Armstrong C, Wang H, Tracey KJ, Maier SF, Watkins LR: A new model of sciatic inflammatory neuritis (SIN): induction of unilateral and bilateral mechanical allodynia following acute unilateral peri-sciatic immune activation in rats. Pain 2001, 94:231-244.

68. Chen RG, Kong WW, Ge DL, Luo C, Hu SJ: Bilateral mechanical and thermal hyperalgesia and tactile allodynia after chronic compression of dorsal root ganglion in mice. Neurosci Bull 2011, 27:233-240.

69. Ohmichi Y, Sato J, Ohmichi M, Sakurai H, Yoshimoto T, Morimoto A, Hashimoto T, Eguchi K, Nishihara M, Arai YC, Ohishi H, Asamoto K, Ushida T, Nakano T, Kumazawa T: Two-week cast immobilization induced chronic widespread hyperalgesia in rats. Eur J Pain 2012, 16:338-348.

70. Hossaini M, Sarac C, Jongen JL, Holstege JC: Spinal glycinergic and GABAergic neurons expressing C-fos after capsaicin stimulation are increased in rats with contralateral neuropathic pain. Neuroscience 2011, 196:265-275.

71. Vanderah TW, Suenaga NM, Ossipov MH, Malan TP Jr, Lai J, Porreca F: Tonic descending facilitation from the rostral ventromedial medulla mediates opioid-induced abnormal pain and antinociceptive tolerance. J Neurosci. Offic J Soc Neurosci 2001, 21:279-286.

72. Svensson Cl, Tran TK, Fitzsimmons B, Yaksh TL, Hua XY: Descending serotonergic facilitation of spinal ERK activation and pain behavior. FEBS Lett 2006, 580:6629-6634

73. Zanon RG, Cartarozzi LP, Victorio SC, Moraes JC, Morari J, Velloso LA, Oliveira AL: Interferon (IFN) beta treatment induces major histocompatibility complex (MHC) class I expression in the spinal cord and enhances axonal growth and motor function recovery following sciatic nerve crush in mice. Neuropathol Appl Neurobiol 2010, 36:515-534.

74. Marsh BJ, Williams-Karnesky RL, Stenzel-Poore MP: Toll-like receptor signaling in endogenous neuroprotection and stroke. Neuroscience 2009, 158:1007-1020.

75. Rivest S: Regulation of innate immune responses in the brain. Nat Rev Immunol 2009, 9:429-439.

76. Yanai H, Ban T, Wang Z, Choi MK, Kawamura T, Negishi H, Nakasato M, Lu Y, Hangai S, Koshiba R, Savitsky D, Ronfani L, Akira S, Bianchi ME, Honda K, Tamura T, Kodama T, Taniguchi T: HMGB proteins function as universal sentinels for nucleic-acid-mediated innate immune responses. Nature 2009, 462:99-103.

77. Zhang Q, Raoof M, Chen Y, Sumi Y, Sursal T, Junger W, Brohi K, Itagaki K, Hauser CJ: Circulating mitochondrial DAMPs cause inflammatory responses to injury. Nature 2010, 464:104-107.

78. Stewart CR, Stuart LM, Wilkinson K, van Gils JM, Deng J, Halle A, Rayner KJ, Boyer L, Zhong R, Frazier WA, Lacy-Hulbert A, El Khoury J, Golenbock DT, Moore KJ: CD36 ligands promote sterile inflammation through assembly of a toll-like receptor 4 and 6 heterodimer. Nat Immunol 2010, 11:155-161.

79. Shichita T, Hasegawa E, Kimura A, Morita R, Sakaguchi R, Takada I, Sekiya T, Ooboshi H, Kitazono T, Yanagawa T, Ishii T, Takahashi H, Mori S, Nishibori M, Kuroda K, Akira S, Miyake K, Yoshimura A: Peroxiredoxin family proteins are key initiators of post-ischemic inflammation in the brain. Nat Med 2012, 18:911-917.

80. Zhang J, Takahashi HK, Liu K, Wake H, Liu R, Maruo T, Date I, Yoshino T, Ohtsuka A, Mori S, Nishibori M: Anti-high mobility group box-1 monoclonal antibody protects the blood-brain barrier from ischemia-induced disruption in rats. Stroke 2011, 42:1420-1428.

81. Cavassani KA, Ishii M, Wen H, Schaller MA, Lincoln PM, Lukacs NW, Hogaboam CM, Kunkel SL: TLR3 is an endogenous sensor of tissue necrosis during acute inflammatory events. J Exp Med 2008, 205:2609-2621.

82. Erridge C: Endogenous ligands of TLR2 and TLR4: agonists or assistants? J Leukoc Biol 2010, 87:989-999.

83. Kariko $\mathrm{K}, \mathrm{Ni} \mathrm{H}$, Capodici J, Lamphier M, Weissman D: mRNA is an endogenous ligand for toll-like receptor 3. J Biol Chem 2004, 279:12542-12550.

84. Hosmane S, Tegenge MA, Rajbhandari L, Uapinyoying P, Kumar NG, Thakor $\mathrm{N}$, Venkatesan A: Toll/interleukin-1 receptor domain-containing adapter inducing interferon-beta mediates microglial phagocytosis of degenerating axons. J Neurosci 2012, 32:7745-7757.

85. Tanaka T, Ueno M, Yamashita T: Engulfment of axon debris by microglia requires p38 MAPK activity. J Biol Chem 2009, 284:21626-21636.

86. Liu T, Gao YJ, Ji RR: Emerging role of toll-like receptors in the control of pain and itch. Neurosci Bull 2012, 28:131-144.

doi:10.1186/1742-2094-10-148

Cite this article as: Stokes et al:: Toll-like receptor signaling adapter proteins govern spread of neuropathic pain and recovery following nerve injury in male mice. Journal of Neuroinflammation 2013 10:148.

\section{Submit your next manuscript to BioMed Central and take full advantage of:}

- Convenient online submission

- Thorough peer review

- No space constraints or color figure charges

- Immediate publication on acceptance

- Inclusion in PubMed, CAS, Scopus and Google Scholar

- Research which is freely available for redistribution 